REVIEW

\title{
Treatment of neonatal seizures
}

\author{
Janet Rennie, Geraldine Boylan
}

Arch Dis Child Fetal Neonatal Ed 2007;92:F148-F150. doi: 10.1136/adc.2004.068551

Newborn babies with unusual movements thought to represent seizures are usually given a loading dose of phenobarbitone without electroencephalography being performed. Antiepileptic drugs (AEDs) are then continued, with the outcome determined by clinical observation alone. AED treatment, often involving multiple drugs for long periods, is undesirable at a time when the brain is developing rapidly and likely to be especially vulnerable to any toxic effects. Despite considerable advances in the pharmacology of AEDs, continuous EEG monitoring using compact digital systems with simultaneous videorecording allowing off-line analysis, automated seizure detection, neuroimaging, and basic science research on cellular mechanisms of brain injury, treatment of such babies has progressed little. A change in practice is long overdue to allow affected babies to benefit from the advances made.

See end of article for authors' affiliations

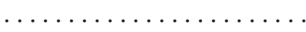

Correspondence to: Dr Rennie, Elizabeth Garrett Anderson Obstetric Hospital, Huntley Street, London WC1E 6DH, UK; janetmrennie@btinternet. com

Accepted 4September 2006

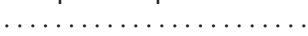

A ny newborn baby with unusual movements which are thought to represent seizures is usually given a loading dose of phenobarbitone without electroencephalography (EEG) being performed. The prescription of antiepileptic drugs (AEDs) is then continued, with "therapeutic success" or failure determined using clinical observation alone. AED treatment often involves multiple drugs given for a period of weeks or months, at a time when the brain is developing rapidly and likely to be especially vulnerable to any toxic effects. Investigation directed at elucidating the cause of the seizures is limited to a cranial ultrasound scan, with estimation of the blood glucose and electrolytes, occasionally including a lumbar puncture. In the four years since this topic was last reviewed for Archives, ${ }^{1}$ there has been considerable progress in the field, with advances in the pharmacology of AEDs, continuous EEG monitoring using compact digital systems with simultaneous videorecording allowing off-line analysis, automated seizure detection, neuroimaging, and basic science research regarding cellular mechanisms of brain injury and the effect of AEDs. In our view a change in practice is long overdue, and babies should be among those who benefit from the advances made, not least the 10 new AEDs that have been licensed since 1990.

The notion that "what you see is what you get" is not true for the neonate with seizures. The phenomenon of electro-clinical dissociation is well recognised in this age group, and there is a very poor correlation between any electrographic signature of seizure and clinical manifestations. ${ }^{2}$ There is increasing evidence that neonatal seizures have an adverse effect on neurodevelopmental outcome and predispose to cognitive, behavioural, or epileptic complications in later life. ${ }^{3}$ In animal studies, seizures impair neurogenesis and derange neuronal structure, function and connectivity. ${ }^{4-6}$ Animal experiments show that seizures alter the growth of hippocampal cells, with apoptosis and "mossy fibre" sprouting of the dentate granule cells and the CA3 part of the hippocampal subfield (abnormal growth of granule cell axons). Although there is some evidence that the neonatal brain is more resistant to this kind of damage than the adult brain, the immature brain is certainly not immune to injury. ${ }^{7}$ The precise mechanisms and pathways by which seizures in early life exert later effects on cognition remain elusive. Intriguing evidence comes from studies in which young rats subjected to pharmacologically induced status epilepticus and then reared in an enriched environment with toys and music performed better in water maze learning tests later on than rats reared in a standard way. Similarly, rats with neonatal seizures who were deprived of maternal contact did worse than those who were reared with their dams. ${ }^{9}$

We and others have demonstrated that seizures are associated with an increase in cerebral blood flow velocity. ${ }^{10}{ }^{11}$ This increase presumably reflects, but may not meet, the pathologically exaggerated demand, and any mismatch is likely to contribute to cell death and damage; undetected and untreated seizure activity certainly increases the insult to the neonatal brain of the rat. ${ }^{12}$ Seizures add to the hypoxic-ischaemic insult in newborn animals, and the same may be true for babies. ${ }^{13}{ }^{14}$ Status epilepticus may be particularly damaging. After kindling (brief but repetitive stimulation resulting in an accelerated and prolonged seizure effect), immature rats, like adults, have a permanent reduction in seizure threshold and are more vulnerable to damage from seizures later in life (the "two hit" hypothesis). ${ }^{15} 16$

In addition to the concern that undiagnosed and untreated subclinical seizures may be damaging to the neonatal brain, new evidence is available on the cellular mechanisms of action and effects of commonly used AEDs. Many AEDs (eg phenytoin) act by modulating voltage-gated sodium or calcium ion channels, whereas others (benzodiazepines, phenobarbitone) act by enhancing the inhibition of the $\gamma$-aminobutyric acid (GABA) receptors, particularly the chloride-permeable GABA $_{\mathrm{A}}$ receptors. ${ }^{17}$ Holmes and his co-workers ${ }^{4}$ have shown that AMPA ( $\alpha$-amino-3-hydroxy-5methyl-4-isoxazolepropionic acid) receptors are

Abbreviations: AED, antiepileptic drug; $E E G$, electroencephalography; GABA, $\gamma$-aminobutyric acid 
present, but silent, in the neonate, and $N$-methyl-D-aspartate (NMDA) channels do not function at normal membrane resting potentials. Ben-Ari ${ }^{18}$ has shown that GABAergic synapses precede glutamate synapses and that receptors are formed before synapses. Many anticonvulsants work by enhancing the opening of $\mathrm{GABA}_{\mathrm{A}}$ channels; when this channel is opened in the usual situation, negatively charged chloride flows into the neurone from the extracellular space because neurones normally have very little chloride in their cytoplasm. This "extra" negative charge means that the neuronal potential is even more negative than usual, making it less likely that the neurone will fire an action potential. Developing neurones express $\mathrm{Na}^{+} / \mathrm{K}^{+} / 2 \mathrm{Cl}^{-}$cotransporter, and this results in accumulation of intracellular chloride. Hence the neonatal neurone has a high chloride content, and consequently the developing brain has a different response to GABA (with an efflux of chloride rather than an influx), so that the response to opening of $\mathrm{GABA}_{\mathrm{A}}$ channels is excitatory rather than inhibitory. Further, $\mathrm{GABA}_{\mathrm{B}}$ receptors probably develop late in the neonatal period and provide little post-synaptic inhibition at this time of life. For all these reasons, "conventional" AEDs (particularly those that potentiate $\mathrm{GABA}_{\mathrm{A}}$ receptors) are likely to prove ineffective in the newborn. $\mathrm{Na}^{+} / \mathrm{K}^{+} / 2 \mathrm{Cl}^{-}$cotransporter continues to be expressed in rat pups for up to 12 days after birth, before the chloride-exporting transporter takes over, and this explains why seizures are so refractory to treatment with AEDs that act on GABA receptors. ${ }^{19}$

In addition to providing an elegant explanation for the observation that AEDs that are effective in older children and adults do not work in the neonatal period, basic science research has also raised new questions about the safety of currently used AEDs when used in babies with rapidly developing brains. Phenobarbitone, still the most widely used first line AED in the neonatal period, has long been known to have long term effects on brain growth. Newer studies have added to these concerns, with the demonstration of increased apoptotic neurodegeneration in the developing rat brain after exposure to phenobarbitone, phenytoin, and benzodiazepines. ${ }^{20}$ Valproic acid is toxic to the developing brain, as evidenced by the fetal valproate syndrome, with its attendant risks of learning and development disorders. ${ }^{21}$ Newer agents such as topiramate and levetiracetam look more promising in this regard, with no experimental evidence for neurotoxicity in the developing brain at anticonvulsant concentrations..$^{22}$ Topiramate has the additional advantage that it may extend the window of time for which post-ischaemic therapeutic hypothermia is effective. ${ }^{24}$ Recently, there has been the interesting and exciting observation that bumetanide, which is widely used as a diuretic and has a good safety profile, suppresses seizures in rat pups. ${ }^{19}$ There is increasing enthusiasm for a trial of bumetanide as an AED in the newborn. ${ }^{25}$

Very few studies using EEG rather than clinical observation to measure the response to AED treatment of the newborn have been published. In one, about a third of babies responded to either phenobarbitone or phenytoin given as first line with around a further third achieving control when the other agent was added. ${ }^{26}$ In our hands, midazolam was disappointing as a second line AED; babies who responded to phenobarbitone alone were more likely to have a low seizure burden and a relatively normal background EEG. ${ }^{27}$ Midazolam controlled most cases of drug-resistant neonatal seizures in another study, albeit at very high doses. ${ }^{28}$

In our view, the only way forward in this long neglected area is by improved access to EEG and continuous monitoring, with high quality specialised neurophysiology reporting with a rapid turn around time. The lack of specialised skills in the interpretation of neonatal EEG is inhibiting widespread use of the technique.
Given the developments in technology and the possibility of rapid transmission of large volumes of data, centralised reporting is no longer an impossible dream in the UK and could be achieved with broadband transmission to a few continuously (and properly) staffed national reporting stations. Neonatal seizures are relatively rare, and each neonatal unit would only require such a service on a few occasions each year.

The alternative is automated seizure detection, and many groups around the world (including our own) are working hard on this difficult task. As yet, no algorithm has proved robust enough to detect reliably a sufficient number of neonatal seizures to be clinically useful, probably not least because of the varied seizure morphology seen in the neonate. ${ }^{29}{ }^{30}$ However, newly emerging signal-processing methods are constantly being applied to the important problem of automatically detecting neonatal seizures, and the problem may yet be solved. Novel approaches such as motion tracking of neonatal body movements during seizures have been described, but these methods have the major limitation that they will inevitably fail to detect subtle or subclinical seizures, which are common in babies. ${ }^{29}{ }^{31}$ The practical problems associated with the application of multiple EEG electrodes may soon be eased by the development of disposable electrode caps designed specifically for long-term neonatal monitoring. Cerebral function monitoring is probably better than nothing, and can help with seizure recognition and monitoring of treatment in babies with a relatively normal or attenuated background EEG and high-voltage generalised seizures, but is likely to be misleading in those (particularly preterm) with moderately abnormal background EEG and low-voltage or localised seizures. ${ }^{32}$ Multichannel EEG recording with electrodes that comprehensively cover the scalp, particularly the central and temporal areas, will remain the "gold standard" for seizure recognition and have the added benefit that useful prognostic information can often be obtained from the background pattern. Large multicentre trials using continuous EEG monitoring for recognition of seizures and monitoring of therapeutic response are undoubtedly required, and could be facilitated via a centralised reporting system for neonatal EEG, which could recruit patients via the network it serviced. Such trials are particularly vital in the subgroups of babies with hypoxicischaemic encephalopathy and preterm brain injury in order to establish whether or not treatment to electrical quiescence can improve neurodevelopmental outcome. In our view, an objective measure of the seizure burden with EEG would serve to define success (a reduction of the seizure burden by $80 \%$ or more) and would avoid the common problem of over-treating babies who have subtle abnormal clinical signs with multiple AEDs, leading to a prolonged intensive care course and confounding of clinical signs. AEDs suitable for evaluation include topiramate, levetiracetam and perhaps even bumetanide. Babies with seizures are a high-risk group who have been neglected for far too long, receiving a standard of investigation and treatment that is now lagging way behind that offered to older children and adults; for their sakes we urge change.

\section{Authors' affiliations \\ Janet Rennie, University College London Hospitals NHS Foundation Trust, London, UK \\ Geraldine Boylan, Department of Paediatrics \& Child Health, University College Cork, Cork, Ireland \\ Competing interests: None.}

\section{REFERENCES}

1 Levene M. The clinical conundrum of neonatal seizures. Arch Dis Child 2002;86:75-7. 
2 Weiner SP, Painter MJ Geva D et al. Neonatal seizures electroclinical dissociation. Pediatr Neurol 1991;7:363-8.

3 Holmes GL. Effects of seizures on brain development: lessons from the laboratory. Pediatr Neurol 2005;33:1-11.

4 Holmes GL, Khazipov R, Ben-Ari Y. New concepts in neonatal seizures. Neuroreport 2002; 13:A3-8.

5 Wasterlain CG. Effects of neonatal status epilepticus on rat brain development Neurology 1976;26:975-86.

6 McCabe BK, Silveira DC, Cilio MR, et al. Reduced neurogenesis after neonatal seizures. J Neurosci 2001;6:2094-103.

7 Huang L-T, Cilio MR, Silveira DC, et al. Long-term effects of neonatal seizures: a behavioral, electrophysiological, and histology study. Dev Brain Res 1999; 118:99-107.

8 Faverion S, Silveira DC, Fu BH, et al. Beneficial effects of enriched environment following status epilepticus in immature rats. Neurology 2002;59:1356-64.

9 Huang L-T, Holmes GL, Lai MC, et al. Maternal deprivation stress exacerbates cognitive deficits in immature rats with recurrent seizures. Epilepsia 2002;43:1141-8

10 Boylan GB, Panerai RB, Rennie JM, et al. Cerebral blood flow velocity during neonatal seizures. Arch Dis Child 1999;80:F105-10.

11 Borch K, Pryds O, Holm S, et al. Regional cerebral blood flow during seizures in neonates. J Pediatr 1998;132:431-5

12 Wasterlain CG. Recurrent seizures in the developing brain are harmful. Epilepsia 1997; $38: 728-34$

13 Wirrell EC, Armstrong EA, Osman LD, et al. Prolonged seizures exacerbate perinatal hypoxic-ischemic brain damage. Pediatr Res 2001;50:445-54.

14 Miller SP, Weiss J, Barnwell A, et al. Seizure-asociated brain injury in term newborns with perinatal asphyxia. Neurology 2002;58:542-8.

15 Koh S, Storey TW, Santos TC, et al. Early-life seizures in rats increase susceptibility to seizure-induced brain injury in adulthood. Neurology 1999;53:912-21.

16 Hoffman AF, Zhao Q, Holmes GL. Cognitive impairment following status epilepticus and recurrent seizures during early development: support for the "two hit hypothesis". Epilepsy Behav 2004;5:873-7.

17 Kaindl AM, Asimiadou S, Manthey D, et al. Antiepileptic drugs and the developing brain. Cell Mol Life Sci 2006;63:399-413.
18 Ben-Ari Y. Basic developmental rules and their implications for epilepsy in the immature brain. Epileptic Disord 2006;8:91-102.

19 Dzhala VI, Talos DM, Sdrulla DA, et al. NKCC1 transporter facilitates seizures in the developing brain. Nat Med 2005;1 1:1205-13.

20 Bittigau P, Sifringer M, Genz K, et al. Antiepileptic drugs and apoptotic neurodegeneration in the developing brain. Proc Natl Acad Sci USA 2002;99:15089-94.

21 Morrow J, Russell A, Guthrie E, et al. Malformation risks of antiepileptic drugs in pregnancy: a prospective study from the UK epilepsy and pregnancy register. J Neurol Neurosurg Psychiatry 2006;77:193-8

22 Manthey D, Asimiadou S, Steforska V, et al. Sulthiame but not levetiracetam exerts neurotoxic effects in the developing brain. Exp Neurol 2005; 193:497-503.

23 Glier C, Dzietko M, Bittigau P, et al. Therapeutic doses of topiramate are not toxic to the developing brain. Exp Neurol 2004; 185:403-9.

24 Liu Y, Barks JD, Xu G, et al. Topiramate extends the therapeutic window for hypothermia-mediated neuroprotection after stroke in neonatal rats. Stroke 2004;35: 1460-5.

25 Staley KJ. Wrong-Way chloride transport: is it a treatable cause of some intractable seizures? Epilepsy Curr 2006;6:124-7.

26 Painter MJ, Scher MS, Stein AD, et al. Phenobarbital compared with phenytoin for the treatment of neonatal seizures. N Engl J Med 1999;341:485-9.

27 Boylan G, Rennie JM, Chorley G, et al. Second line anticonvulsant treatment of neonatal seizures: a video-EEG monitoring study. Neurology 2004;62:486-8.

28 Castro Conde JR, Borges AAH, Martinez ED, et al. Midazolam in neonatal seizures with no response to phenobarbital. Neurology 2005;64:876-9.

29 Boylan GB, Rennie JM. Automated neonatal seizure detection. Clin Neurophysiol 2006;117:1412-13.

30 Faul S, Boylan G, Connolly S, et al. An evaluation of automated neonatal seizure detection methods. Clin Neurophysiol 2005; 116:1533-41.

31 Karayiannis NB, Tao G, Frost JD Jr, et al. Automated detection of videotaped neonatal seizures based on motion segmentation methods. Clin Neurophysiol 2006;117:1585-94.

32 Rennie JM, Chorley G, Boylan GB, et al. Non-expert use of the cerebral function nmonitor for neonatal seizure detection. Arch Dis Child 2004;89:37-40. 